\title{
A population-based analysis of outcomes for small cell carcinoma of the breast by tumor stage and the use of radiation therapy
}

\author{
Felicia Hare ${ }^{1}$, Smith Giri ${ }^{1}$, Jashmin K Patel ${ }^{2}$, Andrew Hahn ${ }^{1}$ and Michael G Martin ${ }^{2 *}$
}

\begin{abstract}
Purpose: Primary small cell carcinomas of the breast (SCCB) are rare tumors with limited data on outcomes and treatment strategies. Using a population based approach, we aimed to study outcomes of SCCB and determine whether the use of radiation therapy is associated with better survival among patients with SCCB.

Methods: Using the Surveillance, Epidemiology and End Results (SEER) registry, we identified patients with SCCB between 1973 and 2010. We examined the stage specific survival of these patients and compared it to the stage specific survival of small cell lung cancer (SCLC) from the SEER database over the same accrual period. We further analyzed the impact of radiation therapy on overall survival for SCCB patients using a univariate and multivariate approach.

Results: A total of 199 patients with primary SCCB with staging were identified during the study period. Eighty-four patients (42\%) had localized disease, 77 (39\%) had regional disease and 38 (19\%) had distant disease. For comparison, 81,933 patients with SCLC were identified. Outcomes were superior for patients with SCCB with localized (150 vs. 16 months, $p<0.01$ ) and regional disease (56 vs. 13 months, $p<0.01$ ), but not distant disease (7 vs. 7 months, $p=0.43$ ). Use of radiation therapy was not associated with a significant difference in OS for patients with either localized (202 vs. 147 months, $p=0.48$ ) or regional (52 vs. 75 months, $p=0.650$ ) disease.
\end{abstract}

Conclusions: SCCB has a more favorable prognosis by stage for localized and regional disease than SCLC. Adjuvant radiation is not associated with an improvement in survival for patients with localized or regional SCCB in this dataset.

Keywords: Small cell carcinoma; Breast; Neuroendocrine; Radiation; Prognosis

\section{Background}

Small cell carcinomas (SCC) are poorly differentiated neuroendocrine tumors that arise predominantly in the lungs (Grossman et al. 2011). Extrapulmonary small cell carcinomas (EPSCC) comprise $\sim 2.5-5 \%$ of all SCC (van der Heijden and Heijdra 2005). While EPSCCs may occur at various sites, small cell cancer of the breast (SCCB) makes up 4-10\% of all EPSCC (Grossman et al. 2011). Overall, neuroendocrine breast cancers comprise about 2-5\% of all breast cancer cases (Boyd and Hayes 2012).

\footnotetext{
* Correspondence: mmartin@westclinic.com

${ }^{2}$ Department of Hematology/Oncology, The West Cancer Center/University of Tennessee Health Science Center, 1588 Union Ave., Memphis, TN 38104, USA

Full list of author information is available at the end of the article
}

Due to the rarity of SCCB, outcomes and treatment protocols are largely undefined. Treatment may include surgery and adjuvant chemotherapy/radiation therapy depending on tumor size and lymph node status; hormonal therapy is added if the tumor expresses the appropriate receptors (Adams et al. 2014; Adegbola et al. 2005; Shin et al. 2000). Adjuvant chemotherapy regimens include a platinum agent and etoposide since biologic markers of SCCB are similar to that of small cell cancer of the lung (SCLC) (Abbasi et al. 2013; Adegbola et al. 2005; Ge et al. 2012; Ochoa et al. 2012; Sanguinetti et al. 2013; Suhani et al. 2014). The role of radiation therapy in the treatment of SCCB remains controversial; there are no controlled trials definitively highlighting its benefit and or its effect on median overall survival (OS). 
Using a population-based approach in the US, we aimed to study the overall and stage specific outcomes of patients with SCCB and identify the role of radiation therapy in the management of these cases.

\section{Methods}

We utilized the Surveillance, Epidemiology and End Results (SEER) 18 database to identify all patients with primary SCCB between 1973-2010 (Surveillance and End Results (SEER) Program 2013). The SEER database includes data from nine population-based registries covering 1990-1999 and 18 covering 2000-2009, which covers approximately $26 \%$ of cancer patients in the US. It classifies cancer histology and topography information on the basis of the third edition of the International Classifications of Diseases for Oncology (ICD-O-3).

Cases of SCCB were identified in the SEER database using the appropriate ICD-O-3 codes for small cell cancer and oat cell cancer, which were 8041/3 and 8043/3. The results were further categorized by primary site breast using the codes C500-C506 and C508-C509. Cases with more than one primary were excluded. Patients identified as having SCCB were further classified as having localized, regional, and distant disease per SEER staging, which does not list staging in traditional clinical stages I-IV.

For comparison purposes, all cases of primary small cell lung cancer (SCLC) were identified during the same study period. These cases were identified using location codes C340-C343 and C348 respectively. SCLC patients were further classified as having localized, regional, and distant disease based on SEER summary stage.

Statistical analyses were conducted using Graph Pad Prism 6 and Statistical Package for Social Sciences (SPSS) version 21.0 (IBM Corporation, Armonk NY). Correlations between categorical variables were made using the chi-squared test. Median survivals were calculated using the Kaplan-Meier method. Differences in survival were computed using log-rank test (MantelCox). Cox regression analysis was used for multivariate analysis using age, gender, race, tumor stage and the use of surgery and radiation therapy. All p-values were 2sided and the level of significance was at 0.05 .

\section{Results}

A total of 199 patients with primary SCCB were identified using the study criteria. The median age was 65 years (range 28-97) and 98\% were females. Among these patients, 84 (42\%) had localized disease, 77 (39\%) had regional disease and 38 (19\%) had distant disease. Breast surgery was undertaken in $95 \%$ of patients with localized disease and $88 \%$ of patients with regional disease. A total of 69 patients (35.9\%) received radiation therapy. A comparison of various demographic and clinical characteristics among patients with and without radiation therapy is shown in Table 1.

Table 1 Comparison of demographic and clinical characteristics among patients treated with and without radiation therapy

\begin{tabular}{llll}
\hline Category & No Radiation therapy & Radiation therapy & P value \\
\hline Number of patients* & 123 & 69 & $61(28-88)$ \\
Median age at diagnosis, yr & $68(37-97)$ & 69 & \\
Median survival, m & 58 & $59(85.5 \%)$ \\
Race & $109(88.6 \%)$ & $10(14.5 \%)$ \\
- White & $10(8.1 \%)$ & 0 \\
- Black & $3(2.4 \%)$ & 0 \\
- Others & $1(0.8 \%)$ & $69(100 \%)$ \\
- Unknown & $119(96.7 \%)$ & \\
Female \% & & $53(76.8 \%)$ \\
Surgery & $99(80.5)$ & $15(21.7 \%)$ \\
- Yes & $21(17.1 \%)$ & $1(1.5 \%)$ \\
- No & $3(2.4 \%)$ & \\
- Unknown & & $11(15.9 \%)$ \\
Staging & $26(21.1 \%)$ & $28(40.6 \%)$ \\
- Distant & $54(43.9 \%)$ & $30(43.5 \%)$ \\
- Localized & $43(35 \%)$ & \\
- Regional & & 0.28 \\
\hline
\end{tabular}

$\mathrm{yr}$, year; $\mathrm{m}$, months.

* the use of radiation therapy was unknown in 7 patients. 
The median overall survival (OS) varied by stage and was found to be 150 months $(\mathrm{m}), 56 \mathrm{~m}$ and $7 \mathrm{~m}(\mathrm{p}<$ 0.001 ) for localized, regional, and distant disease respectively (Figure 1). A total of 81,933 cases of SCLC were identified during the same time period for comparison. The median OS was higher for patients with SCCB as compared to SCLC in patients with localized (150 m vs. $16 \mathrm{~m}, \mathrm{p}<0.001$ ) (Figure 2a) and regional disease (56 m vs. $13 \mathrm{~m}, \mathrm{p}<0.001$ ) (Figure $2 \mathrm{~b}$ ). However, the median OS for distant disease was similar for both SCCB and SCLC (7 m vs. $7 \mathrm{~m}, \mathrm{p}=0.43$ ) (Figure 2c).

In univariate analysis, no significant difference between the median OS of patients treated with and without radiation therapy was noted. On subgroup analysis, radiation therapy was not associated with significantly different median OS for patients with either localized (202 m vs. $147 \mathrm{~m}, \mathrm{p}=0.477$ ) (Figure $3 \mathrm{a}$ ) or regional disease (52 m vs. $75 \mathrm{~m}, \mathrm{p}=0.650$ ) (Figure $3 \mathrm{~b}$ ). The difference in survival remained non-significant after adjusting for age, race and receipt of surgery in the multivariate analysis (Tables 2 and 3). Further, we tested if the combination of radiation therapy with surgery led to any survival differences in patients with local and regional disease by testing the interactions of these two variables in the multivariate model. However, the differences in OS continued to remain non-significant.

\section{Discussion}

Primary SCCB is a rare disease with limited available data. Many of the reports in the literature are case reports or small case series and much of the information is anecdotal. The paucity of data creates difficulties in prognostication and treatment strategies, leaving outcomes largely undefined. Our study provides limited insight into the management of this rare disease by revealing the outcomes of SCCB by stage and showing no correlation between treatment with radiation therapy and overall survival, especially in patients with earlier disease.

Studies have shown that SCCB bears a clinical resemblance to more common forms of breast cancer, while also sharing histologic and morphologic features with SCLC (Adegbola et al. 2005; Ge et al. 2012; Jochems and Tjalma 2004). While some sources show that SCCB is as aggressive as its pulmonary counterpart, others have suggested SCCB has a more favorable prognosis, especially if caught in the early stages of the disease (Adams et al. 2014; Adegbola et al. 2005; Shin et al. 2000; Rovera et al. 2008; Jochems and Tjalma 2004; Yerushalmi et al. 2009). In contrast to SCLC, our results show that SCCB carries a more favorable prognosis in localized and regional disease. However, distant SCCB has dismal outcomes similar to SCLC. In an earlier study using the SEER registry, Grossman et al. showed that SCCB has the highest overall 5- and 10- year survival among all cases of EPSCC (Grossman et al. 2011). Another populationbased study from the UK showed similar results (Wong et al. 2009). Studies have shown that EPSCC cases tend to present at earlier stages as compared to patients with SCLC (Subramanian et al. 2008). This translates into a better overall prognosis in patients with SCCB as compared to other forms of small cell cancer. Timely detection seems to be the key as the

\section{Primary S mall Cell of the Breast by stage}

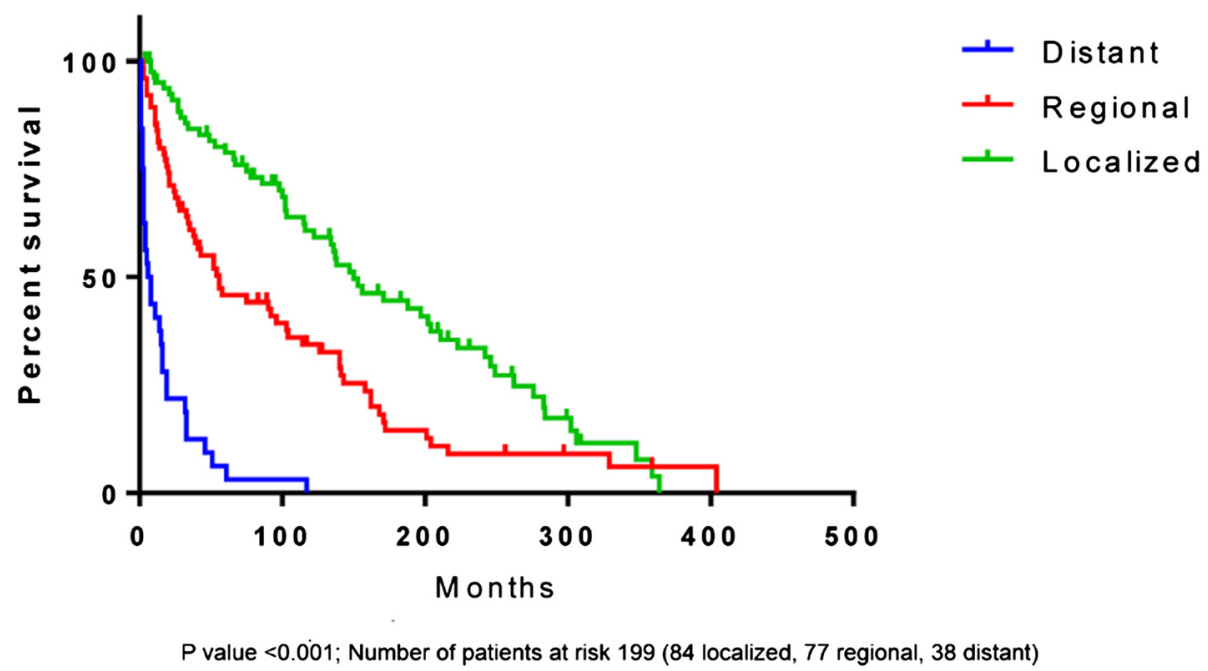

Figure 1 Kaplan Meier Survival curves of primary small cell cancer of the breast by stage. Log rank test was statistically significant with $p$ value $<0.001$. 
a) OS of $S \mathrm{~m}$ all cell of the breast versus SCLC, localized dz

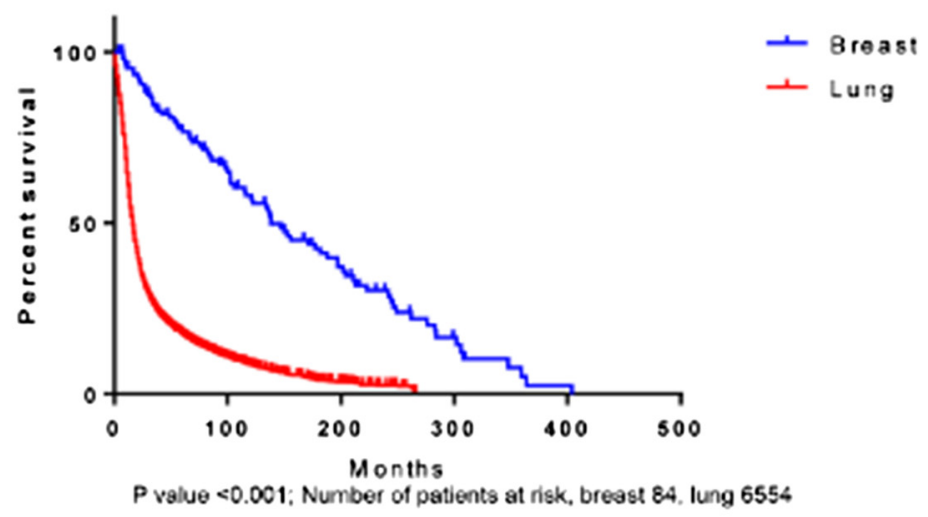

b) OS of Small cell of the breast versus SCLC, regionaldz

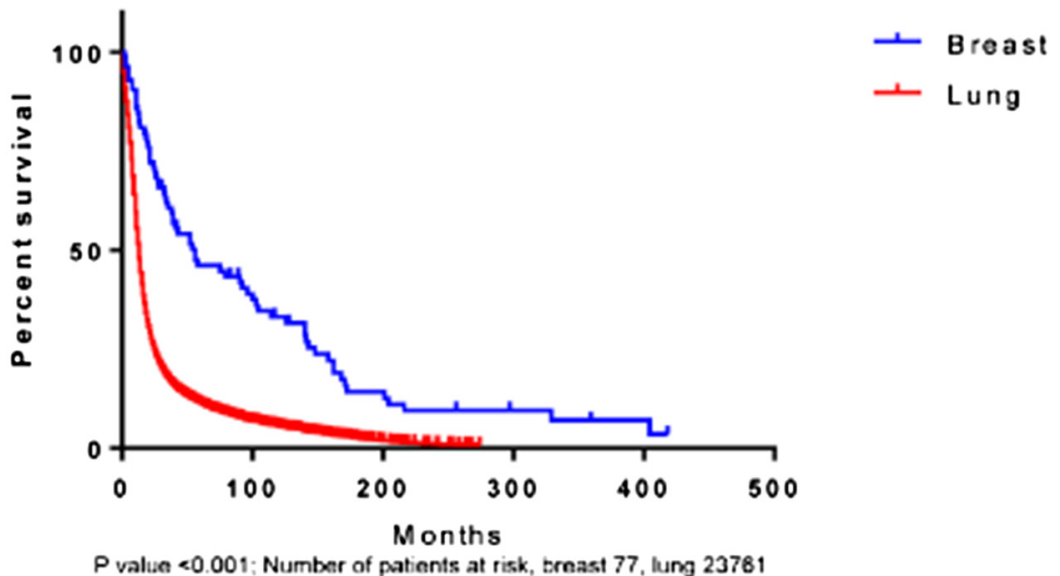

c)

OS of Small cell of the breast versus SCLC, distant dz

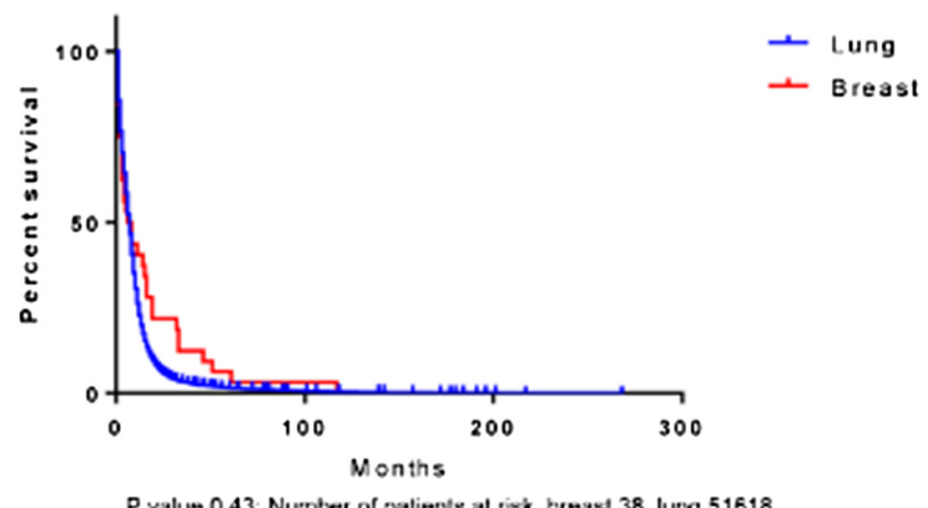

Figure 2 Kaplan Meier Survival curves of primary small cell cancer of the breast and small cell cancer of the lung according to different stages. a: Localized disease b: Regional disease. c: Distant disease. The survival curves were significantly different for localized and regional disease ( $p$ value $<0.001$ in both cases) but not for distant disease ( $p$ value 0.43 ). 
a) Influence of XRT on localized small cell of the breast

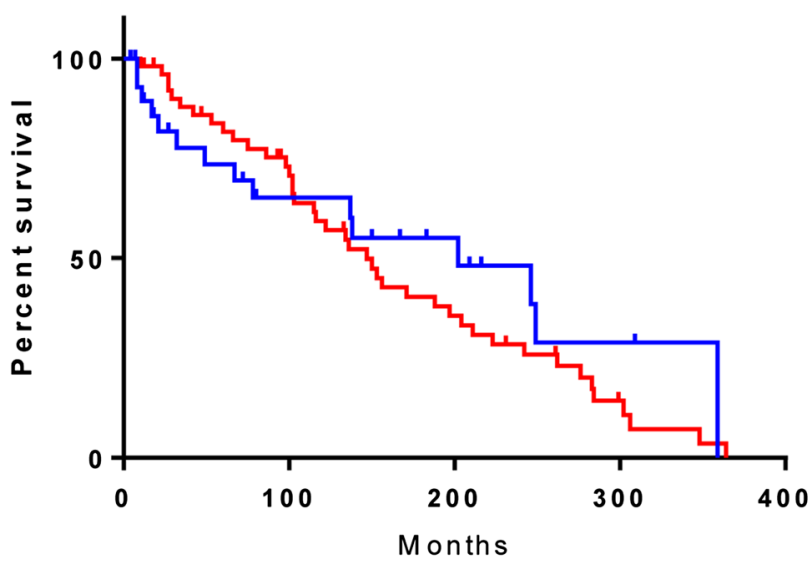

- Radiation

I No Radiation

b) Influence of XRT on regionalsmall cell of the breast

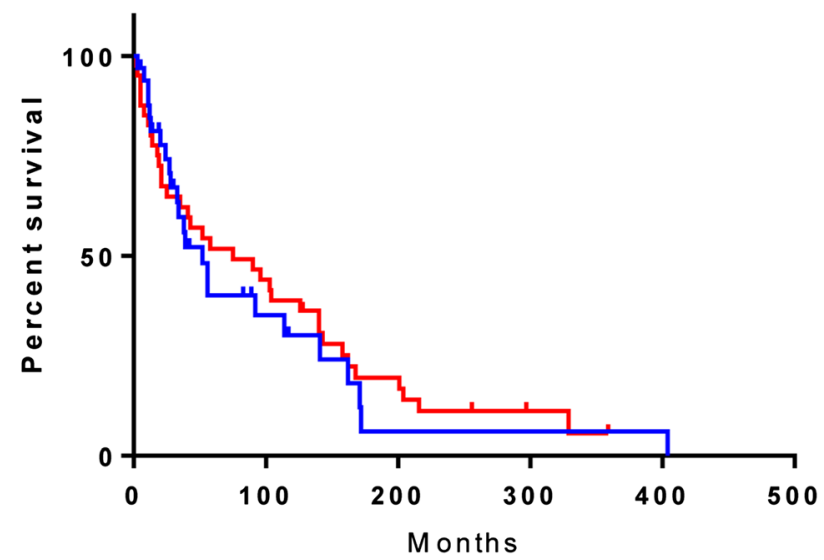

Figure 3 Kaplan Meier Survival curves of primary small cell cancer of the breast with and without radiation. a: Localized disease b: Regional disease.

Table 2 Multivariate Cox proportional hazard regression model for patients with localized SCCB

\begin{tabular}{llll}
\hline Category $^{*}$ & HR & $\mathbf{9 5 \% ~ C l ~ o f ~ H R ~}$ & $\boldsymbol{P}$ value \\
\hline Radiation therapy vs no radiation & 0.68 & $0.36-1.31$ & 0.25 \\
Age group & - & - & 0.01 \\
- (50-70) vs <50 years & 0.88 & $0.29-2.59$ & \\
- > 70 years vs <50 years & 2.34 & $0.82-6.98$ & \\
Race & - & - & 0.27 \\
- Black versus white & 2.15 & $0.27-16.84$ & 0.46 \\
- Others versus white & 0.08 & $0.01-2.42$ & 0.15 \\
Surgery vs no surgery & 0.01 & $0.01-0.25$ & $<0.01$ \\
\hline
\end{tabular}

$\mathrm{HR}$, hazard ratio; $\mathrm{Cl}$, confidence interval; vs, versus.

* a total of 81 cases included in this multivariate analysis.
Table 3 Multivariate Cox proportional hazard regression model for patients with regional SCCB

\begin{tabular}{llll}
\hline Category* & HR & $\mathbf{9 5 \% ~ C l ~ o f ~ H R ~}$ & $\boldsymbol{P}$ value \\
\hline Radiation therapy vs no radiation & 0.97 & $0.55-1.71$ & 0.93 \\
Age group & - & - & 0.01 \\
- (50-70) vs $<50$ years & 2.45 & $1.10-5.46$ & 0.03 \\
$->70$ vs $<50$ years & 3.24 & $1.46-7.17$ & $<0.01$ \\
Race & - & - & $<0.01$ \\
- Black versus white - & 4.59 & $1.75-4.59$ & $<0.01$ \\
Others versus white & 0.40 & $0.05-3.10$ & 0.03 \\
Surgery vs no surgery & 0.72 & $0.29-1.74$ & 0.47 \\
\hline
\end{tabular}

$\mathrm{HR}$, hazard ratio; $\mathrm{Cl}$, confidence interval; vs, versus.

* a total of 72 cases included in this multivariate analysis. 
median overall survival drastically declines as the cancer metastasizes.

Since SCCB is rare and has not been extensively studied, treatment strategies are numerous and no recommended treatment protocol exists to guide clinicians. A combination of surgery, ranging from breast conserving to modified radical mastectomy, with adjuvant chemotherapy has been suggested in the treatment of localized and regional SCCB (Adams et al. 2014; Adegbola et al. 2005; Shin et al. 2000; Ge et al. 2012; Zekioglu et al. 2003; Murthy et al. 2013; Yildirim et al. 2011; Lopez-Bonet et al. 2008; Nicoletti et al. 2010; Haji et al. 2009; Navrozoglou et al. 2011; Yamasaki et al. 2000; Wei et al. 2010). The use of radiation therapy remains controversial in the literature (Wei et al. 2010; Yildirim et al. 2011; Navrozoglou et al. 2011). In our study, no association existed between overall survival for SCCB and treatment with radiation therapy, especially among patients with localized or regional disease. A prior study by Grossman et al. had shown a beneficial role for surgery and radiation therapy among all cases of EPSCC. However, the same study failed to show a significant survival benefit among the subgroup of patients with SCCB, which is in agreement with our findings (Abbasi et al. 2013).

It should be noted that our data for radiation therapy in SCCB is from a non-randomized population based sample. Despite performing a multivariate analysis for several risk factors affecting survival, we acknowledge our limitation of not including other variables, such as tumor size, tumor grade, chemotherapy usage, and hormone receptor status, which may have affected our observations. Other limitations of this study include the inability to verify the accuracy of coding; however, SEER databases are rigorously maintained and undergo quality monitoring. The strengths of our study include a large sample size in a population-based setting that enables us to study this rare malignancy.

\section{Conclusions}

In summary, primary SCCB is an extremely rare form of breast carcinoma, which presents challenges for diagnosis, prediction of outcomes, and overall treatment strategies. Based on our SEER database review, SCCB has a more favorable prognosis than SCLC for localized and regional malignancy. The reasons for this cannot be elucidated at this time without further study of this rare carcinoma. However, it highlights the importance of early screening measures in overall survival because once the disease has progressed to a distant site, the prognosis is no longer appreciably improved over that of SCLC. The lack of a well-defined treatment protocol poses a difficulty for clinicians. This population-based database review shows no association between the use of radiation therapy for localized or regional SCCB and overall survival, which brings into question the use of radiation in treatment protocols.

\section{Competing interests}

The authors declare that they have no competing interests.

\section{Authors' contributions}

MGM and SG developed the initial research question and performed data analysis. FH, JKP, AH, and SG wrote the original manuscript. AH, SG, and MGM made all revisions to the manuscript. All authors read and approved the final manuscript.

\section{Acknowledgements}

This study utilized the SEER database. The interpretation of this data is the sole responsibility of the authors. The authors acknowledge the efforts of the New York State Cancer Registry, New York State Department of Health, and the SEER program tumor registries in the creation of the SEER database. This study was provided an IRB exempt status by the Institutional Review Board at the University of Tennessee of Tennessee Health Science Center.

\section{Author details}

${ }^{1}$ Department of Internal Medicine, The University of Tennessee Health Science Center, Memphis, USA. ²Department of Hematology/Oncology, The West Cancer Center/University of Tennessee Health Science Center, 1588 Union Ave., Memphis, TN 38104, USA.

Received: 27 February 2015 Accepted: 3 March 2015

Published online: 21 March 2015

\section{References}

Abbasi NZ, Zahur Z, Sheikh AS, Khan AA, Ali F, Memon KH, Moizuddin SS, Loya A, Barkat N (2013) Solid neuroendocrine carcinoma of the breast. J Coll Physicians Surg Pak 23(10):820-822, doi: 11.2013/jcpsp.820822

Adams RW, Dyson P, Barthelmes L (2014) Neuroendocrine breast tumours: breast cancer or neuroendocrine cancer presenting in the breast? Breast 23(2):120-127, doi: 10.1016/j.breast.2013.11.005

Adegbola T, Connolly CE, Mortimer G (2005) Small cell neuroendocrine carcinoma of the breast: a report of three cases and review of the literature. J Clin Pathol 58(7):775-778, doi: 10.1136/jcp.2004.020792

Boyd AS, Hayes BB (2012) Metastatic small cell neuroendocrine carcinoma of the breast. J Cutan Pathol 39(11):1042-1046, doi: 10.1111/j.1600-0560.2012.01970.X

Ge QD, Lv N, Cao Y, Wang X, Tang J, Xie ZM, Xiao XS, Liu P, Xie XM, Wei WD (2012) A case report of primary small cell carcinoma of the breast and review of the literature. Chin J Cancer 31(7):354-358, doi: 10.5732/cjc.012.10012

Grossman RA, Pedroso FE, Byrne MM, Koniaris LG, Misra S (2011) Does surgery or radiation therapy impact survival for patients with extrapulmonary small cell cancers? J Surg Oncol 104(6):604-612, doi:10.1002/jso.21976

Haji AG, Sharma S, Vijaykumar DK, Mukherjee P, Babu RM, Chitrathara K (2009) Primary mammary small-cell carcinoma: A case report and review of the literature. Indian journal of medical and paediatric oncology : official journal of Indian Society of Medical \& Paediatric Oncology 30(1):31-34, doi: 10.4103/0971-5851.56334

Jochems L, Tjalma WA (2004) Primary small cell neuroendocrine tumour of the breast. Eur J Obstet Gynecol Reprod Biol 115(2):231-233, doi: 10.1016/j. ejogrb.2003.12.013

Lopez-Bonet E, Alonso-Ruano M, Barraza G, Vazquez-Martin A, Bernado L, Menendez JA (2008) Solid neuroendocrine breast carcinomas: incidence, clinico-pathological features and immunohistochemical profiling. Oncol Rep 20(6):1369-1374

Murthy V, Geethamala K, Kumar B, Sudharao M (2013) Primary neuroendocrine carcinoma of breast: a rare case report. Annals of medical and health sciences research 3(Suppl 1):S35-S37, doi: 10.4103/2141-9248.121218

Navrozoglou I, Vrekoussis T, Zervoudis S, Doukas M, Zinovieva I, Fotopoulos A, Paschopoulos M, Plachouras N, latrakis G, Dousias V (2011) Primary atypical carcinoid of the breast: a case report and brief overview of evidence. World J Surg Oncol 9:52, doi: 10.1186/1477-7819-9-52

Nicoletti S, Papi M, Drudi F, Fantini M, Canuti D, Tamburini E, Possenti C, Pasquini E, Brisigotti M, Ravaioli A (2010) Small cell neuroendocrine tumor of the breast in a 40 year-old woman: a case report. J Med Case Rep 4:201, doi: 10.1186/1752-1947-4-201

Ochoa R, Sudhindra A, Garcia-Buitrago M, Romilly AP, Cortes J, Gomez H, Rocha Lima CM, Silva O (2012) Small-cell cancer of the breast: what is the optimal 
treatment? A report and review of outcomes. Clin Breast Cancer 12(4):287-292, doi: 10.1016/j.clbc.2012.03.007

Rovera F, Masciocchi P, Coglitore A, La Rosa S, Dionigi G, Marelli M, Boni L, Dionigi R (2008) Neuroendocrine carcinomas of the breast. Int J Surg 6 Suppl 1:S113-115, doi:10.1016/j.jjsu.2008.12.007

Sanguinetti A, Santoprete S, Lucchini R, Triola R, Loreti F, Avenia N (2013) A rare breast tumor: solid neuroendocrine carcinoma. Ann Ital Chir 84(1):81-85

Shin SJ, DeLellis RA, Ying L, Rosen PP (2000) Small cell carcinoma of the breast: a clinicopathologic and immunohistochemical study of nine patients. Am J Surg Pathol 24(9):1231-1238

Subramanian J, Vamsidhar V, Goodgame BW, Govindan R, Morgensztern D (2008) Distinctive Characteristics of extrapulmonary small cell carcinoma: A Surveillance Epidemiology and End Results (SEER) analysis. Paper presented at the American Society of Clinical Oncology. Illinois, Chicago

Suhani AS, Desai G, Thomas S, Aggarwal L, Meena K, Kumar J, Jain M, Tudu SK (2014) Primary neuroendocrine carcinoma breast: our experience. Breast Dis 34(3):95-99, doi: 10.3233/bd-130357

Surveillance, Epidemiology, and End Results (SEER) Program (http://www.seer. cancer.gov) SEER*Stat 8.1.2 Database: Incidence - SEER 18 Regs Research Data, Nov 2013 Sub (1973-2010) < Katrina/Rita Population Adjustment > Linked To County Attributes - Total U.S., 1969-2012 Counties, National Cancer Institute, DCCPS, Surveillance Research Program, Surveillance Systems Branch, released April 2014, based on the November 2013 submission.

van der Heijden HF, Heijdra YF (2005) Extrapulmonary small cell carcinoma. South Med J 98(3):345-349, doi: 10.1097/01.smj.0000145724.40477.50

Wei B, Ding T, Xing Y, Wei W, Tian Z, Tang F, Abraham S, Nayeemuddin K, Hunt K, Wu Y (2010) Invasive neuroendocrine carcinoma of the breast: a distinctive subtype of aggressive mammary carcinoma. Cancer 116(19):4463-4473, doi: 10.1002/cncr.25352

Wong YN, Jack RH, Mak V, Henrik M, Davies EA (2009) The epidemiology and survival of extrapulmonary small cell carcinoma in South East England, 1970-2004. BMC Cancer 9:209, doi: 10.1186/1471-2407-9-209

Yamasaki T, Shimazaki H, Aida S, Tamai S, Tamaki K, Hiraide H, Mochizuki H, Matsubara O (2000) Primary small cell (oat cell) carcinoma of the breast: report of a case and review of the literature. Pathol Int 50(11):914-918

Yerushalmi R, Hayes MM, Gelmon KA (2009) Breast carcinoma-rare types: review of the literature. Ann Oncol 20(11):1763-1770, doi: 10.1093/annonc/mdp245

Yildirim Y, Elagoz S, Koyuncu A, Aydin C, Karadayi K (2011) Management of neuroendocrine carcinomas of the breast: A rare entity. Oncology letters 2 (5):887-890, doi: 10.3892/ol.2011.320

Zekioglu O, Erhan Y, Ciris M, Bayramoglu H (2003) Neuroendocrine differentiated carcinomas of the breast: a distinct entity. Breast 12(4):251-257

\section{Submit your manuscript to a SpringerOpen ${ }^{\circ}$ journal and benefit from:}

- Convenient online submission

- Rigorous peer review

- Immediate publication on acceptance

- Open access: articles freely available online

- High visibility within the field

- Retaining the copyright to your article

Submit your next manuscript at $>$ springeropen.com 